\title{
Experimental Study of the effects of Throttle valve on Auto-cascade Refrigeration System
}

\author{
Zheng Da-yu ${ }^{1, a^{*}}$, Liu Lei ${ }^{2, b}$, Gao Li-ping ${ }^{3, c}$ Chen shuo ${ }^{4, d}$, Chen Qiu-yan, ${ }^{5, e}$, Yu \\ Haifeng ${ }^{6, f}$, Li Xiang $^{7, g}$, Li Jie ${ }^{8, h}$ \\ ${ }^{1}$ School of Energy and Civil Engineering of Harbin Commercial University \\ Harbin, 150028, China
}

Fax086-451-84865269, superteacher73@126.com

${ }^{2}$ School of Energy and Civil Engineering of Harbin Commercial University China

Liulei249425395@126.com

${ }^{3-8}$ School of Energy and Civil Engineering of Harbin Commercial University China

970086053@qq.com

\begin{abstract}
Keywords: Auto-cascade refrigeration system; Mixed working medium; Throttle valve opening; Refrigeration efficiency

Abstract. The objection of this article is to optimize auto-cascade refrigeration system. This refrigeration system use multiple mixture (R22/R23/R14) as the refrigerant, which is driven by the single-stage compressor. Throttle is an important composition of auto-cascade refrigerant system, which impact on evaporation temperature and refrigeration efficiency. This article concrete on experimental study on throttle opening and length of capillary. The comparing data reflect the influence of the throttle valve on refrigeration efficiency. So as to improve working efficiency of all non - azeotropic auto-cascade refrigeration system. It offers data and reference for the auto cascade refrigeration system theory in the future.
\end{abstract}

\section{Introduction}

Auto-cascade refrigeration system(ACR) make full use of multistage cascade refrigeration theory, which use non - azeotropic refrigerant. It achieved $-100^{\circ}$ Cand even lower temperature with a single compressor. It simplify multilevel cascade refrigerant system. Auto-cascade refrigeration system use mixture as refrigerant, using the method of single stage or multistage condensation to make the refrigerants with different boiling to separate step by step, and cascade between high and low boiling for the purpose to achieve low evaporation temperature. Many factors have crucial effect on auto-cascade refrigeration system, such as refrigeration charge, the ratio of refrigeration and even gas-liquid separation degree. However, as the system has it own intrinsic property, throttle element has great influence on evaporation temperature and COP.

Throttle control the flow of valve though the end super-heating degree of evaporator. If throttle opening is too big, leading to refrigerant flow rate is larger, then evaporating pressure and evaporator temperature will increase, at the same time, temperature decreasing speed of evaporator will slow, causing bad valve and cannot reaching the desired temperature. On the contrary, small opening of throttle valve result in refrigerant flow rate decrease, then refrigeration capacity cut down and the temperature decreasing speed of evaporator is slower. Thus throttle valve plays an important role on evaporator. In addition, capillary length has great influence on refrigeration efficiency. Therefore the effect of throttle valve on auto-cascade refrigeration is studied in this article, including throttle opening and capillary length.

\section{Auto-cascade Refrigeration Circle}

As shown in figure 1, the process of the auto-cascade refrigeration is described as: A certain proportion of the non- azeotropic mixed R22/R23/R14 is compressed in the compressor to reach a high temperature and pressure. Then three kinds of refrigerants gas through the condenser $\mathrm{C}$ to 
condense, and most R22 is condensed into liquid, but middle boiling R23 and low boiling R14 is remain vapor. The mixture flows through the liquid separator E1 and it is separated into gas-liquid two phase. The liquid containing R22 flow out through the end of separator, after it runs though exchanger F1 and thermal expansion valve, it enter gas-liquid separator to evaporate in order to make the temperature of separator $\mathrm{E} 230^{\circ} \mathrm{C}$ in constant. The mixed gas escaping from D enter gas-liquid E2, most R23 is condensed into liquid and it is separated from R14 by gravity. After R23 liquid flow out from the bottom of tank E2 and enter the plate heat exchanger F2 and thermal expansion valve, it evaporate in $\mathrm{E} 3$ to control the temperature of $\mathrm{E} 3$ as a constant level $-70^{\circ} \mathrm{C}$. Similarly, R14 gas in the separating tank E3 is condensed into liquid by R23, R14 liquid through plate heat exchanger F3 to get cooled and valve, then evaporate in evaporator to make the evaporator temperature to $-90^{\circ} \mathrm{C}$. The return vapor in evaporator go though heat exchanger F1,F2 and F3, then reach gas-liquid separator and return to compressor, so as to complete a whole refrigeration cycle.

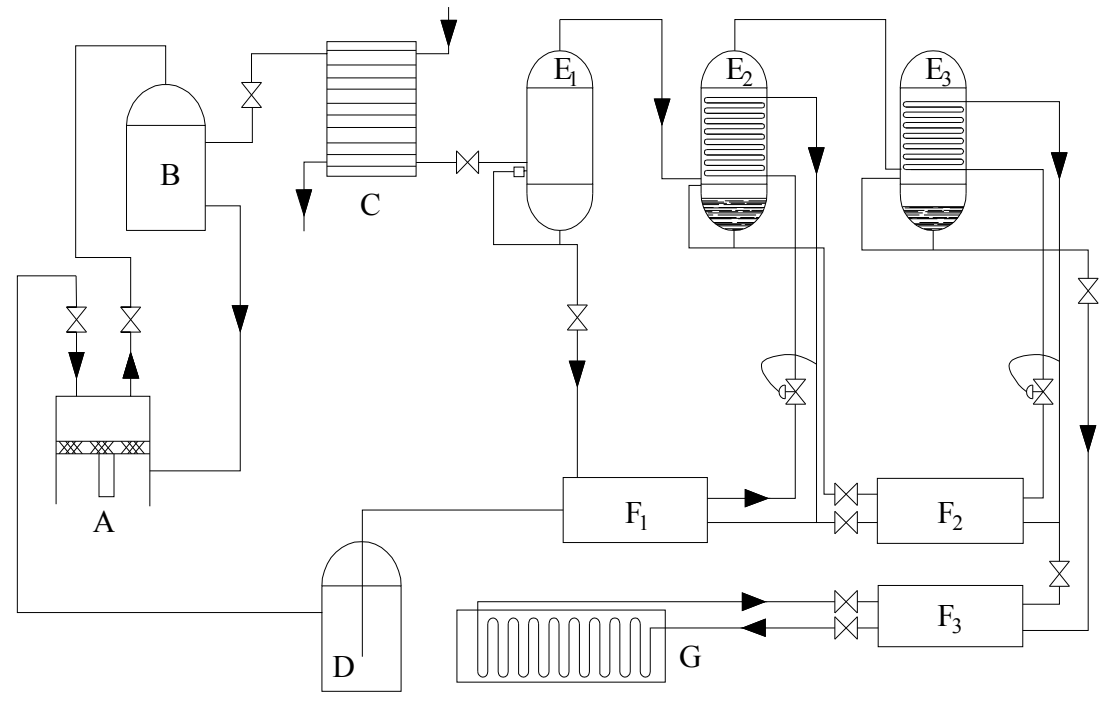

\section{A-Compressor B-Oil Separator C-Condenser D-Gas-liquid Separator $\mathrm{E} 1 \sim \mathrm{E} 3$ - gas-liquid seperator $\mathrm{F} 1 \sim \mathrm{F} 3$-regenerator $\mathrm{G}$ - Gas-liquid Separator}

Figure 1 A Flow chart of Auto Cascade Refrigeration Cycle

\section{Experimental device and conditions}

Ternary non-azeotropic mixture(R22/R23/R14) is used as the refrigerant.The net size of low temperature trunk is $500 \mathrm{~mm} \times 400 \mathrm{~mm} \times 380 \mathrm{~mm}$, polyurethane foaming material with $250 \mathrm{~mm}$ in thick is chose as thermal insulation material. 4DC-5.2-40S semi-hermetic refrigeration compressor from Bitzer is selected,its power is $5 \mathrm{p}$.We select H0M-H3 series of plate heat exchanger and its heat exchange area is $1.5 \mathrm{~m}^{2}$,thermocouple temperature measurement method is used to measure the temperature of measurement points.Low temperature thermal expansion valve produced by red leaves self-control refrigeration company.As the experiments need to explore the capillary length correspond to changes of evaporation temperature, R14 refrigerant use the capillary $3.4 \mathrm{~m}$ and $2.5 \mathrm{~m}$ in length, which can change length during the process of experimental.

This experiment need to maintain indoor temperature $11.3^{\circ} \mathrm{C}$ and condensed water temperature $1.1^{\circ} \mathrm{C}$ in constant,avoiding the experimental data caused by environmental conditions change is not accurate. Due to the experiment just discuss the influence of throttle valve's opening for system, thereby maintaining the conditions of each group of experiments are the same as follows.5.63kg R22, $6.94 \mathrm{~kg} \mathrm{R} 23$ and $5.01 \mathrm{~kg} \mathrm{R} 14$ are filed in the device, using $\Phi 3 \times 3.4$ m capillary, separating gas pipeline ball valve opening keep consistent.In this way,avoiding the effects of other factors on the experiment results. Each group of experiments is conducted under the same conditions of other objective factors and environmental factors,so as to guarantee the validity of the comparison between groups of experimental data. 
As this experiment need to study frozen cooling condition, we take $500 \mathrm{ml}$ water as frozen object. After the temperature is equal to room temperature then take it into evaporation box. Evaporation temperature sensors is hanging in the water in vertical to ensure the measuring length of temperature sensor is submerged in water completely and it does not contact with the walls of the water container. Then adjust the throttle and carry on the experiment.

\section{Results and discussion}

Throttle valve is a valve to control fluid flow by changing the throttling section or valve length . So the change of the throttle valve mainly have two aspects, namely the throttle opening and the length of capillary. Thus this article mainly analyses how the throttle opening and capillary length affects the evaporation temperature.

\begin{tabular}{ccccccc}
\hline $\begin{array}{c}\text { Time } \\
(\mathrm{min})\end{array}$ & 1.50 & 1.50 & 1.50 & 1.50 & 1.50 & 1.50 \\
& $\begin{array}{c}\text { Tank }\left({ }^{\circ} \mathrm{C}\right) \\
0\end{array}$ & $\begin{array}{c}1.50 \\
\operatorname{Tank}\left({ }^{\circ} \mathrm{C}\right)\end{array}$ & $\begin{array}{c}1.75 \\
\text { Tank }\left({ }^{\circ} \mathrm{C}\right)\end{array}$ & $\begin{array}{c}1.25 \\
\text { Water }\left({ }^{\circ} \mathrm{C}\right)\end{array}$ & $\begin{array}{c}1.50 \\
\text { Water }\left({ }^{\circ} \mathrm{C}\right)\end{array}$ & $\begin{array}{c}1.75 \\
\text { Water }\left({ }^{\circ} \mathrm{C}\right)\end{array}$ \\
\hline 10 & -15.2 & 11.3 & 11.3 & 11.3 & 11.3 & 11.3 \\
20 & -39.1 & -15.0 & -14.7 & 9.6 & 9.7 & 9.9 \\
30 & -51.3 & -51.8 & -38.7 & 6.0 & 5.9 & 6.1 \\
40 & -59.0 & -60.0 & -51.4 & 1.4 & 1.2 & 1.4 \\
50 & -65.6 & -68.2 & -69.3 & -0.9 & -1.2 & -1.0 \\
60 & -67.6 & -71.3 & -68.3 & -1.5 & -1.9 & -1.7 \\
70 & -68.9 & -73.1 & -69.5 & -1.8 & -2.3 & -2.0 \\
80 & -69.9 & -74.5 & -70.5 & -2.3 & -2.7 & -2.3 \\
90 & -70.5 & -75.2 & -71.3 & -2.5 & -3.0 & -2.5 \\
100 & -71.5 & -75.9 & -72.1 & -2.8 & -3.7 & -2.8 \\
110 & -72.4 & -76.9 & -73.0 & -3.0 & -4.0 & -3.1 \\
120 & -73.1 & -77.7 & -73.7 & -3.4 & -4.4 & -3.4 \\
130 & -73.7 & -78.5 & -74.5 & -3.8 & -5.4 & -3.9 \\
140 & -74.1 & -79.0 & -75.0 & -4.1 & -12.2 & -4.3 \\
150 & -74.1 & -79.1 & -75.1 & -5.5 & -25.3 & -5.8 \\
\hline
\end{tabular}

\section{Length of the capillary experiment}

Main throttle valve of auto- cascade refrigeration equipment adopts the capillary. As a kind of throttling element, inner diameter and length of capillary has an important influence on temperature and pressure. Because diameter of $\Phi 2$ and $\Phi 2.5$ is too small and the required length is very short. Therefore, this article selects a $\Phi 3 \times 3.4 \mathrm{~m}$ capillary and a $\Phi 3 \times 2.5 \mathrm{~m}$ capillary to conduct contrast experiment. Get the relationship between capillary length and the evaporation temperature is shown in table 1.

Table 1Cooling process of different lengths of capillary

\begin{tabular}{cccccccccc}
\hline $\begin{array}{c}\text { Length } \\
(\mathrm{m})\end{array}$ & $\begin{array}{c}\mathrm{t}=0 \\
(\mathrm{~min})\end{array}$ & $\begin{array}{c}\mathrm{t}=10 \\
(\mathrm{~min})\end{array}$ & $\begin{array}{c}\mathrm{t}=20 \\
(\mathrm{~min})\end{array}$ & $\begin{array}{c}\mathrm{t}=30 \\
(\mathrm{~min})\end{array}$ & $\begin{array}{c}\mathrm{t}=40 \\
(\mathrm{~min})\end{array}$ & $\begin{array}{c}\mathrm{t}=50 \\
(\mathrm{~min})\end{array}$ & $\begin{array}{c}\mathrm{t}=60 \\
(\mathrm{~min})\end{array}$ & $\begin{array}{c}\mathrm{t}=70 \\
(\mathrm{~min})\end{array}$ & $\begin{array}{c}\mathrm{t}=80 \\
(\mathrm{~min})\end{array}$ \\
\hline 3.4 & -4.7 & -60.8 & -75.8 & -84.1 & -90.3 & -93.4 & -94.1 & -94.5 & -94.7 \\
2.5 & -4.2 & -56.8 & -68.0 & -72.2 & -76.3 & -77.8 & -78.9 & -79.2 & -79.4 \\
\hline
\end{tabular}

The measured data is converted to graph, as shown in figure5. 


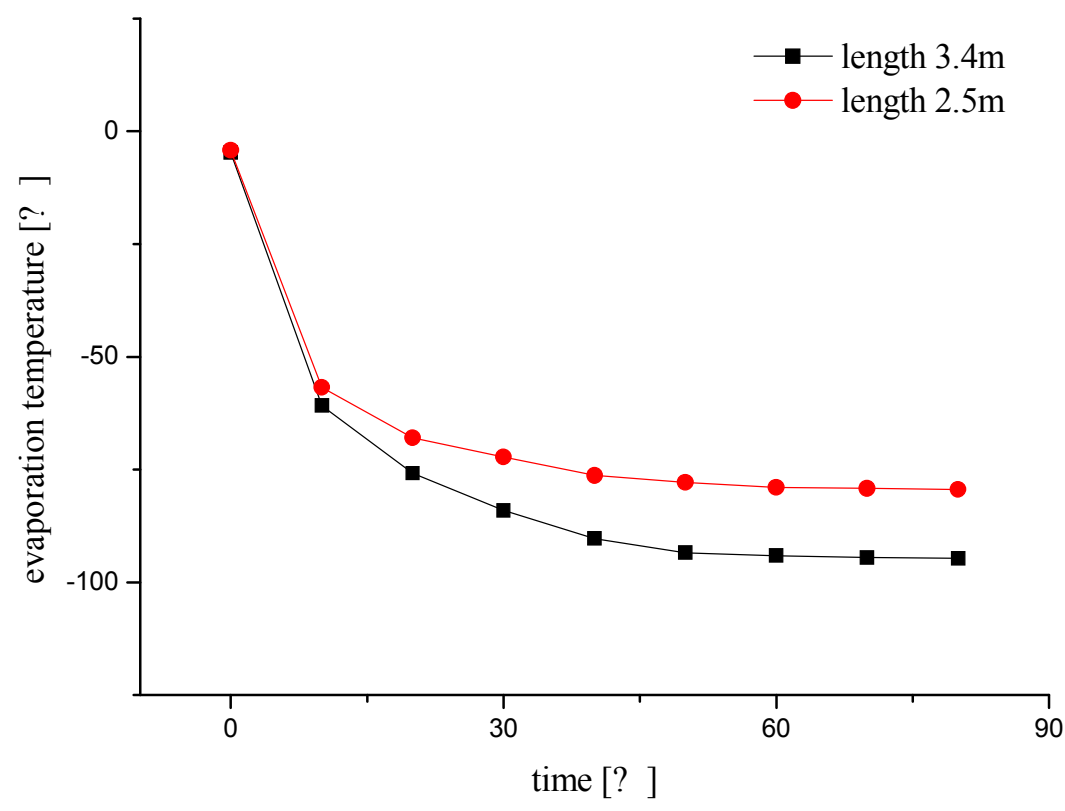

Figure 2 Change curve of evaporation temperature with different capillary

In this condition, the Change of water temperature with different length of the capillary in evaporation tank is showed as table 2 .

Table 2 Water temperature changes with different length of the capillary

\begin{tabular}{cccccccccc}
\hline \multirow{2}{*}{ Length $(\mathrm{m})$} & $\begin{array}{c}\mathrm{t}=0 \\
(\mathrm{~min})\end{array}$ & $\begin{array}{c}\mathrm{t}=20 \\
(\mathrm{~min})\end{array}$ & $\begin{array}{c}\mathrm{t}=40 \\
(\mathrm{~min})\end{array}$ & $\begin{array}{c}\mathrm{t}=60 \\
(\min )\end{array}$ & $\begin{array}{c}\mathrm{t}=80 \\
(\min )\end{array}$ & $\begin{array}{c}\mathrm{t}=100 \\
(\min )\end{array}$ & $\begin{array}{c}\mathrm{t}=120 \\
(\min )\end{array}$ & $\begin{array}{c}\mathrm{t}=140 \\
(\min )\end{array}$ & $\begin{array}{c}\mathrm{t}=160 \\
(\min )\end{array}$ \\
\hline 3.4 & 11.3 & 5.9 & -1.2 & -2.3 & -3.0 & -3.7 & -4.4 & -12.2 & -37.1 \\
2.5 & 11.3 & 6.4 & 1.6 & -1.1 & -1.6 & -2.1 & -2.5 & -3.1 & -3.9 \\
\hline
\end{tabular}

\section{Acknowledgements}

Heilongjiang Province Natural Science Fund Project: NumberE201231

Heilongjiang Province Graduate Innovation Fund Project: NumberYJSCX2013-240HSD

\section{References}

[1]Liu Jinping, $\mathrm{Wu}$ xiao,Guo Lingbing. The experimental study of throttle valve opening on heat transfer performance of the auto-cascade refrigeration condensation evaporator [J].Refrigeration technology,2011, 39(3):66-71.

[2] ZhaoLi, Gao Pan. Evaluation of zeotropic refrigerants based on nonlinear relationship between temperature and enthalpy[J].Science in China Series E,2006,49(3):322-331.

[3]Zhang Yiming.Energy efficiency research of multiple refrigerator auto-cascade refrigeration system[D]. Harbin university of commerce.2013:24-35

[4] Xu Xiongwen, liu Jinping, Le Cao.Mixed refrigerant composition shift due to throttle valves opening in auto cascade refrigeration system[J].Chinese Journal of Chemical Engineering,2014:1-5.

[5]Wang Shenglong,Chen Gguangming,Wang Qin.Throttle valve opening experiment research on Auto- cascade refrigeration[J].Newspaper of refrigeration,2005,26(4):56-58. 